\title{
Individual-level Associations Between Indicators of Social Capital and Alcohol Use Disorders Identification Test Scores in Communities With High Mortality in Korea
}

\author{
Jang-Rak Kim, Baekgeun Jeong, Ki-Soo Park, Yune-Sik Kang \\ Department of Preventive Medicine and Institute of Health Sciences, Gyeongsang National University College of Medicine, Jinju, Korea
}

Objectives: This study examined associations among social capital indicators (social participation and generalized trust) at the individual level and alcohol use, which was quantified using Alcohol Use Disorders Identification Test (AUDIT) scores.

Methods: In total, there were 8800 participants in community health interviews, including 220 adults sampled systematically from a resident registration database of each of 40 sub-municipal administrative units of local (city or county) governments. Adjusted odds ratios (aORs) and 95\% confidence intervals (Cls) were calculated using polychotomous logistic regression.

Results: The aORs for abstainers versus people with AUDIT scores of 0-7, based on 3 questions on generalized trust, in comparison to those with no positive responses, were 1.15 (95\% Cl, 0.99 to 1.34) for 1 positive response, 1.16 (95\% Cl, 0.98 to 1.37) for 2 positive responses; and $1.39(95 \% \mathrm{Cl}, 1.20$ to 1.61$)$ for 3 positive responses. The aORs for abstainers versus people with AUDIT scores of $0-7$, in comparison to participation in no organizations, were $0.61(95 \% \mathrm{Cl}, 0.54$ to 0.69$)$ for participation only in informal organizations; 2.16 $(95 \% \mathrm{Cl}, 1.57$ to 2.99$)$ for participation only in religious organizations; 2.41 (95\% Cl, 1.10 to 5.29 ) for participation only in volunteer organizations; and 0.65 (95\% Cl, 0.57 to 0.74$)$ for participation in formal organizations. Participants in formal social organizations, regardless of their participation in informal organizations, were more likely to have AUDIT scores of $8-15$ (aOR, $1.29 ; 95 \% \mathrm{Cl}, 1.04$ to 1.60$)$ or $\geq 16$ (aOR, $1.65 ; 95 \% \mathrm{Cl}, 1.22$ to 2.23 ) than to have scores of $0-7$.

Conclusions: Our findings may have implications for health policy to reduce alcohol problems.

Key words: Social participation, Trust, Religion, Substance abuse

\section{INTRODUCTION}

The harmful use of alcohol is a major risk factor for disease, disability, and death worldwide. Globally, in 2016, 5.3\% of

Received: December 9, 2019 Accepted: May 7, 2020

Corresponding author: Jang-Rak Kim, MD, DrPH

Department of Preventive Medicine and Institute of Health Sciences, Gyeongsang National University College of Medicine, 15 Jinju-daero 816beon-gil, Jinju 52727, Korea

E-mail: jrkim@gnu.ac.kr

This is an Open Access article distributed under the terms of the Creative Commons Attribution Non-Commercial License (https://creativecommons.org/licenses/bync/4.0/) which permits unrestricted non-commercial use, distribution, and reproduction in any medium, provided the original work is properly cited. deaths and $5.1 \%$ of disability-adjusted life years were estimated to be attributable to alcohol use [1].

Both individual and social factors, including sex, age, socioeconomic status, economic wealth, culture, alcohol availability, and social capital, influence alcohol consumption [2,3]. Evidence of associations between social capital and health behaviors has accumulated [4]. Among aspects of social capital, social participation and trust - which are known to influence each other-are considered the most important [5].

Studies have shown that individual-level indicators of social capital such as social participation or trust are negatively associated with the use of alcohol among adolescents [6-10], while a longitudinal study found that higher social capital was asso- 
ciated with increased binge drinking by students [11]. In research on the associations between individual-level social capital and alcohol consumption in adults, the directions of the observed relationships have been inconsistent and inconclusive and depend on the dimension of social capital analyzed, the type of alcohol measure, the country researched [12], and potentially the form of data collection used (that is, with or without an interviewer). While some studies have found negative associations $[13,14]$ between overall social capital and heavy alcohol use, another found no clear association [15]. Similarly, depending on the study, associations between social participation and high alcohol consumption have been found to be negative [16], non-existent $[17,18]$, or positive [12,19-22]. A study of college students showed that formal social participation was negatively associated with heavy drinking, while informal social participation was positively associated with higher alcohol use [23]. Associations between social trust and heavy alcohol use were found in several studies to be negative $[18,24,25]$ and in one to be positive [22].

Most studies in this field have used dichotomous variables, with the presence of hazardous drinking, binge drinking, harmful alcohol consumption, problem drinking, or episodic heavy drinking as dependent variables. However, this approach fails to reflect U-shaped or J-shaped associations between alcohol consumption and all-cause mortality [26]. In a meta-analysis, mortality risk was found to be higher in abstainers than in light-to-moderate drinkers and highest in heavy drinkers [27]. Heavy drinking refers to alcohol use that exceeds a defined threshold of frequency or quantity. In reflection of the broad continuum of adverse health effects associated with the quantity or pattern of alcohol use, alcohol use disorders (AUDs) are heterogeneous and include heavy drinking, hazardous drinking, harmful drinking, and alcohol abuse and dependence [26].

The World Health Organization (WHO) developed a 10-item questionnaire, the Alcohol Use Disorders Identification Test (AUDIT), to screen for AUDs in primary health care settings [28]. The WHO guidelines indicate that AUDIT scores of 0-7 represent abstinence or relatively low-risk drinking; scores of 8-15 represent hazardous alcohol use, and scores of 16 and above indicate the harmful use of alcohol, including alcohol dependence [29].

In this study, we investigated potential associations between individual-level indicators of social capital (social participation and generalized trust) and alcohol use. We measured alcohol use via AUDIT scores because of the implications of this scoring system for health policies designed to reduce the burden associated with alcohol use.

\section{METHODS}

\section{Study Population and Data Collection}

The data were taken from community health interviews conducted in 40 sub-municipal administrative units (each of which is called a myeon, eup, or dong) of cities or counties with high mortality rates. The interviews were conducted between August and October in 2010, 2011, and 2012 as part of the Health Plus Happiness Plus Projects, a collection of strategies to address regional health inequalities in Gyeongsangnam-do Province in Korea. The 8800 study participants included 220 from each administrative unit who were sampled systematically using a resident registration database. The interviewees were adults aged 19 years or older with the earliest birth month and day of the year in their respective households. Trained interviewers conducted door-to-door interviews to collect information regarding socio-demographics, measures of social capital, and health behaviors, including alcohol use. The average response rate was $74.8 \%$ in 2010 (17 areas), $72.0 \%$ in 2011 (12 areas), and $70.3 \%$ in 2012 (11 areas). Additional details have been reported elsewhere [30].

\section{Measures}

\section{Generalized trust}

Generalized trust was chosen as a measure of social trust. To obtain consistent answers, generalized trust was assessed with 3 questions used in the Health Survey for England conducted by the National Center for Social Research [31] and in the European Social Survey [32]. The questions were: "Generally speaking, would you say that most people can be trusted, or you can't be too careful in dealing with people?" with responses of "can be trusted," "can't be too careful," or "don't know"; "Would you say that most of the time, people try to be helpful or just look out for themselves?" with responses of "try to be helpful," "look out for themselves," or "don't know"; and "Do you think most people would take advantage of you if they got the chance, or would they try to be fair?" with responses of "take advantage," "try to be fair," or "don't know."

Generalized trust was analyzed as a quantitative variable with possible values of $0,1,2$, or 3 , indicating the number of positive responses to the 3 questions. 


\section{Social participation}

To measure social participation, participants were asked whether and how actively (very actively, actively, neither actively nor inactively, not actively, or not at all actively) they were involved in formal groups (political parties, school associations, religious meetings, women's clubs, environmental groups, groups for youth or older people, volunteer groups, unions, or neighborhood watch groups) and informal groups (social gatherings, adult education groups, sports groups, or other groups). If participants reported levels of participation as "not active" or "not at all active," their responses were recoded as "no participation." Though religious and volunteer organizations are listed above as formal organizations, we considered them separate categories for the purposes of this study because participation in religious meetings or in individual volunteerism has been found to be significantly associated with heavy alcohol use in previous studies $[12,13,16]$.

Social participation was analyzed as a categorical variable of "no participation," "only in informal organization(s)," "only in religious organization(s)," "only in volunteer organization(s)," or "in formal organization(s) regardless of participation in informal, religious, or volunteer organization(s)."

\section{Alcohol use}

To assess the quantity and pattern of individual alcohol use, we used the Korean version of the AUDIT. The AUDIT consists of 10 questions about recent alcohol use, symptoms of alcohol dependence, and alcohol-related problems. The total score ranges from 0 to 40 and reflects the extent of alcohol consumption and related problems along a broad continuum of severity [33]. For analysis, AUDIT scores were categorized as $0-7,8-15$, and $\geq 16$.

Participants were asked whether they had consumed any alcohol (except as part of ancestral rites) during their lifetime and during the past 12 months. Participants who answered in the affirmative to both questions were then asked the $10 \mathrm{AU}$ DIT questions. Participants who had never consumed any alcohol in their entire life were coded as lifetime abstainers. Those who had consumed alcohol previously, but not in the previous 12 months, were categorized as former drinkers, as in a WHO report [2]. Both lifetime abstainers and former drinkers were coded as abstainers for the analysis.

\section{Socio-demographics, self-rated health, and perceived stress}

The socio-demographic factors of sex, age, marital status, educational level, occupation, level of food security, and ad- ministrative unit of residence (myeon, eup, or dong) were included as covariates in the analyses. Based on participants' responses, marital status was categorized into 4 groups: living with a spouse; not married (age $\geq 30$ years); not married (age $\leq 29$ years); and divorced, widowed, or other. Educational level was defined as the highest educational degree completed by the respondent and was categorized as no education, elementary school, middle or high school, and junior college or more. Participants' occupations were categorized into 7 groups: manager, professional, or clerk; sales or service worker; farmer or fisherman; technical engineer; blue-collar worker; housewife; and other/unemployed. Accurate information regarding household income was difficult to obtain, so we instead used information about household food security, which is a good indicator of household income. For this purpose, we utilized a question from the Canadian Community Health Survey [34]: "Which of the following statements best describes the food eaten in your household in the past year?" Based on responses, household food security was categorized into 4 groups: always enough of the desired foods, usually (but not always) enough of the desired foods, sometimes not enough, and often not enough. The administrative unit of residence (myeon, eup, or dong) was categorized as either an urban (dong) or a rural area (myeon or eup).

As health status is an important correlate of alcohol consumption in older adults, we included self-rated health as a covariate. Participants were asked to rate their own general health on a 5-point scale: very good, good, fair, poor, or very poor. These ratings were ultimately categorized into 3 groups: good, fair, and poor. To assess the presence of hypertension or diabetes, participants were asked if they had been diagnosed with either disease. Finally, we included perceived stress level as an important confounder because it is known to influence alcohol consumption. To measure the amount of perceived stress, we asked a single question: "How stressed do you feel in your daily life?" Perceived stress was categorized into 4 groups: almost none, low, high, and very high.

\section{Statistical Analysis}

For simple analyses, we created cross-tabulations to analyze the associations of socio-demographic variables, self-rated health, and perceived stress with alcohol consumption, with individuals categorized as abstainers or as having AUDIT scores of $0-7,8-15$, or $\geq 16$. The $p$-values were calculated using the chi-square test or analysis of variance. 
Crude and adjusted odds ratios (aORs) and their 95\% confidence intervals ( $\mathrm{Cls}$ ) were assessed with polychotomous logistic regression to analyze the potential associations of generalized trust and social participation in organizations with the dependent variable of alcohol use. The categories of alcohol use were abstainer, AUDIT score of 0-7 (used as the reference group), AUDIT score of 8-15, and AUDIT score $\geq 16$. To estimate aORs, categorized alcohol use was regressed on socio-demographic variables, self-rated health, perceived stress, the presence of hypertension or diabetes, and the social capital indicators of generalized trust and social participation in organizations. An OR greater than 1.0 (or less than 1.0) means that participants were more (or less) likely to be in that alcohol use category than the members of the reference group.

All analyses were performed using SPSS version 21 (IBM Corp., Armonk, NY, USA).

\section{Ethics Statement}

This paper used data from Health Plus Happiness Plus Projects in Gyeongsangnam-do (provincial government), Korea. All participants were informed about the aims of the projects and the confidentiality of the information they would give, and signed the written consent. The data were originally collected for governmental health projects, not for study. So, this study did not require institutional ethics review and approval according to Korean law (the period of data collection from 2010 to 2012).

\section{RESULTS}

Of the 8800 participants, $47.7 \%$ were abstainers. The overall prevalence of current alcohol use was $52.3 \%$. The distribution of AUDIT scores was $35.8 \%$ for $0-7,11.6 \%$ for $8-15$, and $4.9 \%$ for $\geq 16$. All socio-demographic characteristics (sex, age, marital status, educational level, occupation, level of food security, and type of administrative unit of residence), as well as selfrated health, perceived stress, and the presence of hypertension or diabetes, were found to be significantly associated with AUDIT scores (Table 1).

Both generalized trust and social participation in organizations were found to be significantly associated with AUDIT scores in simple analyses. The highest proportion of abstainers was found among respondents who indicated a high level of generalized trust. Similarly, abstainers predominated among those involved in no organizations, only in religious organizations, or only in volunteer organizations. A smaller proportion of those involved in no organizations or only in religious organizations had an AUDIT score $\geq 8$ than among those involved in only informal, only volunteer, or formal organizations (Table 2).

The crude ORs for abstainer status (relative to AUDIT scores of $0-7$ ) for the 3 questions of generalized trust, compared to the group of participants who gave no positive responses, were $1.11(95 \% \mathrm{Cl}, 0.97$ to 1.27$)$ for 1 positive response, $1.17(95 \% \mathrm{Cl}$, 1.01 to 1.36$)$ for 2 , and $1.56(95 \% \mathrm{Cl}, 1.37$ to 1.78$)$ for 3 . The crude ORs for AUDIT scores of 8-15 based on these 3 questions in comparison to the no-positive-response group were 0.87 $(95 \% \mathrm{Cl}, 0.71$ to 1.05$)$ for 1 positive response, $0.94(95 \% \mathrm{Cl}, 0.75$ to 1.16$)$ for 2 , and $0.76(95 \% \mathrm{Cl}, 0.62$ to 0.92$)$ for 3 . The corresponding crude ORs for AUDIT scores $\geq 16$ were $1.01(95 \% \mathrm{Cl}$, 0.76 to 1.33$)$ for 1 positive response, $0.98(95 \% \mathrm{Cl}, 0.72$ to 1.35$)$ for 2 , and 0.82 ( $95 \% \mathrm{Cl}, 0.62$ to 1.10) for 3 (Table 3 ).

The crude ORs for abstainers (relative to AUDIT scores of 0-7), compared to the group of participants who reported no participation in organizations, were $0.51(95 \% \mathrm{Cl}, 0.45$ to 0.57$)$ for participation in only informal organizations, $2.00(95 \% \mathrm{Cl}, 1.47$ to 2.71 ) for only religious organizations, $1.68(95 \% \mathrm{Cl}, 0.79$ to 3.57) for only volunteer organizations, and $0.61(95 \% \mathrm{Cl}, 0.54$ to 0.69) for formal organizations. The crude ORs for AUDIT scores of 8-15, similarly compared to the no-participation group, were $1.17(95 \% \mathrm{Cl}, 0.97$ to 1.41$)$ for participation in only informal organizations, $0.89(95 \% \mathrm{Cl}, 0.49$ to 1.63$)$ for only religious organizations, 2.02 ( $95 \% \mathrm{Cl}, 0.67$ to 6.08 ) for only volunteer organizations, and $1.32(95 \% \mathrm{Cl}, 1.09$ to 1.60$)$ for formal organizations. The corresponding crude ORs for AUDIT scores $\geq 16$ were 0.94 ( $95 \% \mathrm{Cl}, 0.72$ to 1.23$)$ for participation in only informal organizations, 0.29 ( $95 \% \mathrm{Cl}, 0.07$ to 1.19$)$ for only religious organizations, $4.52(95 \% \mathrm{Cl}, 1.49$ to 13.77$)$ for only volunteer organizations, and $1.42(95 \% \mathrm{Cl}, 1.10$ to 1.85$)$ for formal organizations (Table 3).

The aORs for abstainer status (relative to AUDIT scores of 0-7) for the 3 questions of generalized trust, compared to the group of participants who gave no positive responses, were 1.15 (95\% $\mathrm{Cl}, 0.99$ to 1.34$)$ for 1 positive response, $1.16(95 \% \mathrm{Cl}, 0.98$ to 1.37) for 2 , and 1.39 ( $95 \% \mathrm{Cl}, 1.20$ to 1.61) for 3 . The aORs for AUDIT scores of 8-15 based on these 3 questions and compared to the no-positive-response group were $0.92(95 \% \mathrm{Cl}, 0.75$ to 1.13) for 1 positive response, $1.04(95 \% \mathrm{Cl}, 0.83$ to 1.32$)$ for 2 , and $0.89(95 \% \mathrm{Cl}, 0.72$ to 1.11$)$ for 3 . The corresponding aORs for AUDIT scores $\geq 16$ were $1.19(95 \% \mathrm{Cl}, 0.88$ to 1.60$)$ for 1 positive response, $1.20(95 \% \mathrm{Cl}, 0.85$ to 1.68$)$ for 2 , and 1.20 
Table 1. Alcohol Use Disorders Identification Test (AUDIT) scores by socio-demographic characteristics and health indices

\begin{tabular}{|c|c|c|c|c|c|c|c|}
\hline \multirow{2}{*}{ Indices } & \multirow{2}{*}{ Category } & \multirow{2}{*}{ Total (n) } & \multirow{2}{*}{ Abstainers } & \multicolumn{3}{|c|}{ AUDIT score } & \multirow{2}{*}{$p$-value ${ }^{1}$} \\
\hline & & & & $0-7$ & $8-15$ & $\geq 16$ & \\
\hline Sex & Male & 4388 & $1346(30.7)$ & 1736 (39.6) & $905(20.6)$ & $401(9.1)$ & $<0.001$ \\
\hline Age (y) & Mean \pm SD & & $63.5 \pm 14.8$ & $54.3 \pm 15.6$ & $51.1 \pm 14.3$ & $50.9 \pm 12.9$ & $<0.001$ \\
\hline \multirow[t]{2}{*}{ Marital status } & Live with spouse & 5096 & $2090(41.0)$ & $1991(39.1)$ & $718(14.1)$ & $297(5.8)$ & $<0.001$ \\
\hline & Divorced, separation by death, or other & 2855 & $1843(64.6)$ & $780(27.3)$ & $155(5.4)$ & $77(2.7)$ & \\
\hline \multirow[t]{3}{*}{ Educational level } & None & 2171 & $1524(70.2)$ & $529(24.4)$ & $82(3.8)$ & $36(1.7)$ & $<0.001$ \\
\hline & Elementary school & 2111 & $1174(55.6)$ & $688(32.6)$ & $172(8.1)$ & $77(3.6)$ & \\
\hline & Middle or high school & 3541 & $1208(34.1)$ & $1495(42.2)$ & $581(16.4)$ & $257(7.3)$ & \\
\hline \multirow{5}{*}{ Occupation } & Farmer or fisherman & 2147 & $1001(46.6)$ & $753(35.1)$ & $276(12.9)$ & $117(5.4)$ & \\
\hline & Technical engineer & 542 & $116(21.4)$ & $233(43.0)$ & $141(26.0)$ & $52(9.6)$ & \\
\hline & Blue-collar worker & 599 & $211(35.2)$ & $244(40.7)$ & $97(16.2)$ & $47(7.8)$ & \\
\hline & Housewife & 1798 & $1220(67.9)$ & $546(30.4)$ & $24(1.3)$ & $8(0.4)$ & \\
\hline & Other or unemployed & 1788 & $1062(59.4)$ & $510(28.5)$ & $150(8.4)$ & $66(3.7)$ & \\
\hline \multirow[t]{4}{*}{ Food security } & Enough always & 3400 & $1414(41.6)$ & $1385(40.7)$ & $434(12.8)$ & $167(4.9)$ & $<0.001$ \\
\hline & Enough but not always & 4434 & $2201(49.6)$ & $1511(34.1)$ & $517(11.7)$ & $205(4.6)$ & \\
\hline & Sometimes not enough & 775 & $474(61.2)$ & $205(26.5)$ & $56(7.2)$ & $40(5.2)$ & \\
\hline & Often not enough & 191 & $112(58.6)$ & $51(26.7)$ & $11(5.8)$ & $17(8.9)$ & \\
\hline Administrative unit & City (dong) & 6380 & $3224(50.5)$ & $2197(34.4)$ & $693(10.9)$ & $266(4.2)$ & $<0.001$ \\
\hline \multirow{2}{*}{ Perceived stress } & High & 1536 & $648(42.2)$ & $534(34.8)$ & $220(14.3)$ & $134(8.7)$ & \\
\hline & Very high & 371 & $167(45.0)$ & $112(30.2)$ & $53(14.3)$ & $39(10.5)$ & \\
\hline \multirow[t]{2}{*}{ Hypertension } & No & 6468 & $2830(43.8)$ & $2466(38.1)$ & $839(13.0)$ & $333(5.1)$ & $<0.001$ \\
\hline & Yes & 2332 & 1371 (58.8) & $686(29.4)$ & $179(7.7)$ & $96(4.1)$ & \\
\hline \multirow[t]{2}{*}{ Diabetes } & No & 7909 & $3664(46.3)$ & $2914(36.8)$ & $945(11.9)$ & $386(4.9)$ & $<0.001$ \\
\hline & Yes & 891 & $537(60.3)$ & $238(26.7)$ & $73(8.2)$ & $43(4.8)$ & \\
\hline Total & & 8800 & $4201(47.7)$ & 3152 (35.8) & $1018(11.6)$ & $429(4.9)$ & \\
\hline
\end{tabular}

Values are presented as number (\%).

$\mathrm{SD}$, standard deviation.

${ }^{1} \mathrm{By} \chi^{2}$ test for categorical variables and by analysis of variance for age.

(95\% Cl, 0.87 to 1.65$)$ for 3 (Table 4).

The aORs for abstainer status (relative to AUDIT scores of 0-7), compared to the group of participants who reported no participation in organizations, were $0.61(95 \% \mathrm{Cl}, 0.54$ to 0.69$)$ for participation in only informal organizations, $2.16(95 \% \mathrm{Cl}, 1.57$ to 2.99 ) for only religious organizations, $2.41(95 \% \mathrm{Cl}, 1.10$ to 5.29) for only volunteer organizations, and $0.65(95 \% \mathrm{Cl}, 0.57$ to 0.74 ) for formal organizations. The aORs for AUDIT scores of 8-15, similarly compared to the no-participation group, were $1.04(95 \% \mathrm{Cl}, 0.85$ to 1.27$)$ for participation in only informal or- 
Table 2. Alcohol Use Disorders Identification Test (AUDIT) scores by generalized trust and social participation in organizations

\begin{tabular}{|c|c|c|c|c|c|c|c|}
\hline \multirow{2}{*}{ Indices } & \multirow{2}{*}{ Category } & \multirow{2}{*}{ Total (n) } & \multirow{2}{*}{ Abstainers } & \multicolumn{3}{|c|}{ AUDIT score } & \multirow{2}{*}{$p$-value } \\
\hline & & & & $0-7$ & $8-15$ & $\geq 16$ & \\
\hline \multirow[t]{3}{*}{ Generalized trust ${ }^{2}$} & 0 & 1749 & $729(41.7)$ & $674(38.5)$ & $249(14.2)$ & $97(5.5)$ & $<0.001$ \\
\hline & 2 & 1593 & $732(46.0)$ & $579(36.3)$ & $200(12.6)$ & $82(5.1)$ & \\
\hline & 3 & 2898 & $1586(54.7)$ & $939(32.4)$ & $262(9.0)$ & $111(3.8)$ & \\
\hline & Only religious & 291 & $218(74.9)$ & 57 (19.6) & $14(4.8)$ & $2(0.7)$ & \\
\hline & Only volunteer & 48 & $29(60.4)$ & $9(18.8)$ & $5(10.4)$ & $5(10.4)$ & \\
\hline & Formal & 2741 & $1183(43.2)$ & 1012 (36.9) & $369(13.5)$ & $177(6.5)$ & \\
\hline Total & & 8800 & 4201 (47.7) & 3152 (35.8) & $1018(11.6)$ & $429(4.9)$ & \\
\hline
\end{tabular}

Values are presented as number $(\%)$.

${ }^{1}$ By $\chi^{2}$ test.

${ }^{2}$ Number of positive responses to three questions about generalized trust.

${ }^{3}$ By $\chi^{2}$ test for trend.

Table 3. Crude odds ratios for abstainers, Alcohol Use Disorders Identification Test (AUDIT) score 8-15 or $\geq 16$ vs. 0-7 (reference) based on generalized trust and social participation in organizations by polychotomous logistic regression analysis

\begin{tabular}{|c|c|c|c|c|}
\hline \multirow{2}{*}{ Indices } & \multirow{2}{*}{ Category } & \multirow{2}{*}{ Abstainers } & \multicolumn{2}{|c|}{ AUDIT score } \\
\hline & & & 8-15 & $\geq 16$ \\
\hline \multirow[t]{3}{*}{ Generalized trust ${ }^{1}$} & 0 & 1.00 (reference) & 1.00 (reference) & 1.00 (reference) \\
\hline & 2 & $1.17(1.01,1.36)$ & $0.94(0.75,1.16)$ & $0.98(0.72,1.35)$ \\
\hline & 3 & $1.56(1.37,1.78)$ & $0.76(0.62,0.92)$ & $0.82(0.62,1.10)$ \\
\hline \multirow{3}{*}{ Social participation in organizations } & Only religious & $2.00(1.47,2.71)$ & $0.89(0.49,1.63)$ & $0.29(0.07,1.19)$ \\
\hline & Only volunteer & $1.68(0.79,3.57)$ & $2.02(0.67,6.08)$ & $4.52(1.49,13.77)$ \\
\hline & Formal & $0.61(0.54,0.69)$ & $1.32(1.09,1.60)$ & $1.42(1.10,1.85)$ \\
\hline
\end{tabular}

Values are presented as odds ratio (95\% confidence interval).

${ }^{1}$ Number of positive responses to three questions about generalized trust.

ganizations, $0.97(95 \% \mathrm{Cl}, 0.52$ to 1.81) for only religious organizations, 1.97 ( $95 \% \mathrm{Cl}, 0.63$ to 6.15$)$ for only volunteer organizations, and 1.29 ( $95 \% \mathrm{Cl}, 1.04$ to 1.60$)$ for formal organizations. The aORs for AUDIT scores $\geq 16$ based on similar parameters were $0.95(95 \% \mathrm{Cl}, 0.71$ to 1.28$)$ for participation in only informal organizations, $0.32(95 \% \mathrm{Cl}, 0.08$ to 1.37$)$ for only religious organizations, $5.67(95 \% \mathrm{Cl}, 1.73$ to 18.61$)$ for only volunteer organizations, and $1.65(95 \% \mathrm{Cl}, 1.22$ to 2.23$)$ for formal organizations (Table 4).

\section{DISCUSSION}

This study showed that, in communities with high mortality rates in Korea, indicators of social capital were significantly as- sociated with the level of alcohol consumption regardless of the potential confounders of socio-demographic characteristics and health indices. Participants with the highest level of generalized trust or with social participation only in religious or volunteer organizations were more likely to be abstainers than participants with lower levels of generalized trust or those with participation in no organizations, informal organizations only, or formal organizations. Participants in formal social organizations (political parties, school associations, women's clubs, environmental groups, groups for youth or older people, unions, or neighborhood watch groups), regardless of participation in informal organizations (social gatherings or adult education, sports, or other groups), were more likely to have AUDIT scores of 8-15 or $\geq 16$ than those who did not 


\section{Journal of}

Table 4. Adjusted odds ratios for abstainers, Alcohol Use Disorders Identification Test (AUDIT) score 8-15 or $\geq 16$ vs. 0-7 (reference) based on socio-demographic characteristics, health indices, generalized trust, and social participation in organizations by polychotomous logistic regression analysis

\begin{tabular}{|c|c|c|c|c|}
\hline \multirow{2}{*}{ Indices } & \multirow{2}{*}{ Category } & \multirow{2}{*}{ Abstainers } & \multicolumn{2}{|c|}{ AUDIT score } \\
\hline & & & 8-15 & $\geq 16$ \\
\hline \multirow[t]{2}{*}{ Sex } & Male & 1.00 (reference) & 1.00 (reference) & 1.00 (reference) \\
\hline & Female & $2.37(2.08,2.70)$ & $0.19(0.15,0.24)$ & $0.08(0.05,0.13)$ \\
\hline Age (y) & & $1.03(1.02,1.03)$ & $0.98(0.98,0.99)$ & $0.97(0.96,0.98)$ \\
\hline \multirow[t]{4}{*}{ Marital status } & Live with spouse & 1.00 (reference) & 1.00 (reference) & 1.00 (reference) \\
\hline & Not married ( $\geq 30$ y) & $1.44(1.12,1.86)$ & $0.89(0.66,1.21)$ & $0.84(0.57,1.27)$ \\
\hline & Not married ( $\leq 29$ y) & $1.02(0.73,1.41)$ & $0.47(0.31,0.71)$ & $0.25(0.12,0.50)$ \\
\hline & Divorced, separation by death, or other & $0.99(0.87,1.13)$ & $1.07(0.86,1.33)$ & $1.25(0.92,1.70)$ \\
\hline \multirow[t]{4}{*}{ Educational level } & None & 1.00 (reference) & 1.00 (reference) & 1.00 (reference) \\
\hline & Elementary school & $1.11(0.95,1.29)$ & $0.89(0.66,1.21)$ & $0.88(0.57,1.37)$ \\
\hline & Middle or high school & $0.98(0.82,1.16)$ & $1.01(0.74,1.36)$ & $0.91(0.59,1.40)$ \\
\hline & $\geq$ Junior college & $1.13(0.87,1.46)$ & $1.11(0.77,1.61)$ & $0.71(0.41,1.23)$ \\
\hline \multirow[t]{7}{*}{ Occupation } & Manager, professional, or clerk & 1.00 (reference) & 1.00 (reference) & 1.00 (reference) \\
\hline & Sales or service & $0.84(0.66,1.05)$ & $1.28(0.98,1.68)$ & $1.06(0.72,1.56)$ \\
\hline & Farmer or fisherman & $1.15(0.93,1.43)$ & $1.26(0.96,1.64)$ & $1.33(0.91,1.94)$ \\
\hline & Technical engineer & $1.00(0.75,1.34)$ & $1.26(0.94,1.70)$ & $0.94(0.62,1.43)$ \\
\hline & Blue collar worker & $0.93(0.72,1.22)$ & $1.21(0.87,1.67)$ & $1.17(0.75,1.83)$ \\
\hline & House wife & $1.14(0.91,1.42)$ & $0.51(0.31,0.84)$ & $0.63(0.27,1.50)$ \\
\hline & Other or unemployed & $1.43(1.15,1.79)$ & $1.03(0.76,1.38)$ & $0.86(0.56,1.32)$ \\
\hline \multirow[t]{4}{*}{ Food security } & Enough always & 1.00 (reference) & 1.00 (reference) & 1.00 (reference) \\
\hline & Enough but not always & $1.11(0.99,1.24)$ & $1.18(1.01,1.38)$ & $1.17(0.92,1.48)$ \\
\hline & Sometimes not enough & $1.21(0.99,1.49)$ & $1.13(0.80,1.60)$ & $1.68(1.10,2.59)$ \\
\hline & Often not enough & $0.92(0.64,1.34)$ & $0.97(0.48,1.96)$ & $2.93(1.49,5.75)$ \\
\hline \multirow[t]{2}{*}{ Administrative unit } & City (dong) & 1.00 (reference) & 1.00 (reference) & 1.00 (reference) \\
\hline & Rural area (myeon or eup) & $0.84(0.74,0.95)$ & $1.10(0.93,1.31)$ & $1.43(1.12,1.83)$ \\
\hline \multirow[t]{3}{*}{ Self-rated health } & Good & 1.00 (reference) & 1.00 (reference) & 1.00 (reference) \\
\hline & Fair & $0.91(0.80,1.02)$ & $1.21(1.02,1.43)$ & $1.44(1.13,1.84)$ \\
\hline & Poor & $1.41(1.22,1.65)$ & $0.99(0.76,1.27)$ & $1.54(1.10,2.17)$ \\
\hline \multirow[t]{4}{*}{ Perceived stress } & Almost none & 1.00 (reference) & 1.00 (reference) & 1.00 (reference) \\
\hline & Low & $0.89(0.79,1.00)$ & $0.99(0.82,1.19)$ & $1.38(1.02,1.87)$ \\
\hline & High & $0.86(0.73,1.01)$ & $1.35(1.07,1.70)$ & $2.83(2.02,3.96)$ \\
\hline & Very high & $0.88(0.67,1.17)$ & $1.69(1.15,2.48)$ & $3.78(2.33,6.15)$ \\
\hline \multirow[t]{2}{*}{ Hypertension } & No & 1.00 (reference) & 1.00 (reference) & 1.00 (reference) \\
\hline & Yes & $0.95(0.83,1.07)$ & $1.03(0.84,1.26)$ & $1.34(1.01,1.77)$ \\
\hline \multirow[t]{2}{*}{ Diabetes } & No & 1.00 (reference) & 1.00 (reference) & 1.00 (reference) \\
\hline & Yes & $1.34(1.12,1.60)$ & $0.98(0.73,1.32)$ & $1.16(0.80,1.70)$ \\
\hline \multirow[t]{4}{*}{ Generalized trust $^{1}$} & 0 & 1.00 (reference) & 1.00 (reference) & 1.00 (reference) \\
\hline & 1 & $1.15(0.99,1.34)$ & $0.92(0.75,1.13)$ & $1.19(0.88,1.60)$ \\
\hline & 2 & $1.16(0.98,1.37)$ & $1.04(0.83,1.32)$ & $1.20(0.85,1.68)$ \\
\hline & 3 & $1.39(1.20,1.61)$ & $0.89(0.72,1.11)$ & $1.20(0.87,1.65)$ \\
\hline \multirow{5}{*}{$\begin{array}{l}\text { Social participation in } \\
\text { organizations }\end{array}$} & No & 1.00 (reference) & 1.00 (reference) & 1.00 (reference) \\
\hline & Only in informal & $0.61(0.54,0.69)$ & $1.04(0.85,1.27)$ & $0.95(0.71,1.28)$ \\
\hline & Only religious & $2.16(1.57,2.99)$ & $0.97(0.52,1.81)$ & $0.32(0.08,1.37)$ \\
\hline & Only volunteer & $2.41(1.10,5.29)$ & $1.97(0.63,6.15)$ & $5.67(1.73,18.61)$ \\
\hline & Formal & $0.65(0.57,0.74)$ & $1.29(1.04,1.60)$ & $1.65(1.22,2.23)$ \\
\hline
\end{tabular}

Values are presented as adjusted odds ratio (95\% confidence interval).

${ }^{1}$ Number of positive responses to three questions about generalized trust. 
participate in organizations. Therefore, in this study, the effects of social participation on alcohol use seemed to differ depending on the organizations in which people took part: religious, volunteer, informal, or others, including formal organizations.

Herein, we provide evidence that individual-level social capital is associated with alcohol use as measured with AUDIT scores that represented a U-shaped risk of alcohol consumption. Most studies of this subject area have used binary dependent variables and have examined only the presence of heavy or hazardous alcohol use. As a measure of alcohol use, we used the Korean version of the AUDIT questionnaire, which has high reliability, validity, and usefulness as a screening instrument for AUDs in Korea [35]. The AUDIT is currently one of the most frequently used screening tools for alcohol dependence in clinical and epidemiological research [29]. The AUDIT displays good validity for identifying AUDs in the general population, in which the prevalence of alcohol problems is lower than in clinical sample populations [36]. Our analysis also separated abstainers from the AUDIT 0-7 group because they accounted for a substantial portion (48\%) of the study sample and may differ in health status and behaviors. In addition, we conducted face-toface interviews to improve the validity of the data collection.

In this study, generalized trust seemed to be protective against alcohol use. Other studies have found similar results in adults $[18,24,25]$ and adolescents $[6,8,10]$. However, this negative relationship between level of trust and alcohol use was not found in a study in the general Danish population [12]. The inverse association between individual-level interpersonal trust and heavy drinking could be explained in several ways. When facing stress, people with high trust may more easily receive social support instead of adopting unhealthy behaviors such as drinking [37]. They may be more susceptible to advice and recommendations from others, including physicians and public institutions [38]. For example, a patient with high interpersonal trust may follow a physician's advice to stop drinking. Another possible explanation is that people with high interpersonal trust tend to be less lonely [39] and are therefore less likely to use even small amounts of alcohol when meeting others.

As Finlay et al. [23] suggested, we analyzed participation in religious organizations alone separately from participation in formal organizations because attending religious services is both a social activity and a manifestation of faith. Common religions in Korea are Protestantism and Buddhism, which have a precept of abstaining from alcohol. Similar to other studies
$[12,16,23]$, we found that participants in only religious organizations tended to exhibit relatively low alcohol consumption. However, they tended to use alcohol above recommended levels if they were also involved in any other social activities, especially formal organizations.

The results of previous studies of associations between participation in volunteer organizations and drinking are inconsistent. Though individual volunteerism has been found to be protective against heavy alcohol use in studies of college students $[13,16]$ and younger participants [21], volunteer work was found to be associated with risky single-occasion drinking in another study that, like the present study, examined a general population [12]. In the present study, participants in only volunteer organizations were more likely to be abstainers and more likely to have AUDIT scores $\geq 16$ than individuals who did not participate in organizations. Volunteer work may both reduce risky behavior via a set of values and facilitate social opportunities to drink, as suggested by Seid et al. [12].

Social participation in formal and/or informal organizations has been found to be associated with relatively high alcohol use and even heavy or risky alcohol consumption in prior studies [20-23]. These findings were similar to our results, with social participation in formal organizations except for religious organizations or volunteer organizations associated with lowrisk drinking, hazardous drinking, and the harmful use of alcohol, including alcohol dependence. In Korea, people often dine together and consume alcohol after accomplishing an organization's purpose, such as a group discussion or other activity. At these events, alcohol use is widely considered an important means of social interaction, and even "bottoms-up" drinking, or consuming an alcoholic beverage in a single drink, is encouraged. Participants in formal social organizations drink socially; additionally, they exist within social hierarchies determined by age or position and are sometimes influenced to drink under peer pressure. Therefore, participants in formal organizations have frequent opportunities to drink alcohol and even to consume amounts that are greater than what is recommended.

In our study, participation in informal organizations only was also associated with alcohol use, but not with heavy alcohol consumption. Although participants in informal organizations also have many opportunities to drink over meals, they seem to feel less pressure to drink. Membership in informal organizations is determined mainly by the intimacy of the relationship, unlike formal organizations, in which membership largely depends on sociodemographic characteristics. This pattern 
may explain why in the present study, participants in informal organizations tended to drink alcohol, but not too much.

Chuang and Chuang [19] provided evidence for the differential effects of social capital by sex. We calculated sex-specific aORs for indicators of social capital and for AUDIT score categories. Though we do not present the results in this paper, aORs were similar for both sexes, indicating a lack of differential effects. However, the aORs for generalized trust and social participation in organizations for females in the AUDIT-score 8-15 and $\geq 16$ categories were unstable relative to the $0-7$ category because of very small sample sizes, as seen in Table 1.

The present study had some limitations. First, like other studies of social capital and alcohol use, our study was based on cross-sectional survey data. An association in this type of study does not always imply a causal relationship (for example, of social capital on alcohol use). For long-term abstainers, the lack of alcohol use may precede or coincide with the development of the person's current level of generalized trust. Otherwise, reverse causation is very unlikely. For example, it does not follow that abstaining from alcohol use in recent years would increase generalized trust or encourage a person to participate in religious or volunteer organizations. It is unlikely that the more one drinks, the more likely one is to participate in formal organizations. Nevertheless, further research using a cohort design is needed to exclude the possibility of reverse causation. Second, our survey areas were in older and rural communities with high mortality rates, which may limit the generalizability of the results. The proportion of abstainers, $48 \%$ (38\% lifetime abstainers, $10 \%$ former drinkers), in this study was much higher than the 36\% (7\% lifetime abstainers, 29\% former drinkers) previously found in a representative sample in Korea [40]. Third, we did not perform a multilevel analysis to understand the influence of contextual social capital on alcohol use because we measured social capital indicators using aggregated individuallevel questions. According to some studies [13] of alcohol consumption in adolescents or college students that have considered the effects of both individual-level and community-level social capital concurrently, community-level or college-level social capital protects against elevated or harmful alcohol use. However, the relationships between community-level or workplace-level social capital and hazardous drinking are inconsistent in the few studies that have been conducted among adults [14].

High levels of generalized trust, social participation in religious organizations only, and social participation in volunteer organizations only were each found to be protective against alcohol use. Any other social participation in formal and/or informal organizations was associated with alcohol use. Additionally, social participation in formal organizations except for religious services significantly raised the risk of hazardous or harmful alcohol drinking in communities with high mortality in Korea.

\section{CONFLICT OF INTEREST}

The authors have no conflicts of interest associated with the material presented in this paper.

\section{FUNDING}

None.

\section{ACKNOWLEDGEMENTS}

None.

\section{AUTHOR CONTRIBUTIONS}

Conceptualization: JRK, BJ. Data curation: JRK, BJ, KSP, YSK. Formal analysis: JRK. Funding acquisition: None. Methodology: BJ, JRK. Project administration: BJ. Writing - original draft: JRK, BJ, KSP, YSK. Writing - review \& editing: JRK.

\section{ORCID}

Jang-Rak Kim https://orcid.org/0000-0002-8191-5071

Baekgeun Jeong https://orcid.org/0000-0002-1655-5436

Ki-Soo Park https://orcid.org/0000-0001-5571-3639

Yune-Sik Kang https://orcid.org/0000-0002-3404-279X

\section{REFERENCES}

1. World Health Organization. Global status report on alcohol and health 2018 [cited 2019 Nov 28]. Available from: https:// apps.who.int/iris/bitstream/handle/10665/274603/9789241565639-eng.pdf?ua $=1$.

2. World Health Organization. Global status report on alcohol and health 2014 [cited 2019 Nov 28]. Available from: https:// apps.who.int/iris/bitstream/handle/10665/112736/9789240692763_eng.pdf?sequence $=1$. 
3. Victorian Health Promotion Foundation. Reducing alcohol-related health inequities: an evidence summary; 2015 [cited 2019 Nov 26]. Available from: https://www.vichealth.vic.gov. au/-/media/ResourceCentre/PublicationsandResources/HealthInequalities/Fair-Foundations/Summary/\%20Health-Equity_ Summary-Report_Acohol.pdf?la =en\&hash =\%209A176F33C7D55ABFC1A1F50B7BB654530EBC1786.

4. Poortinga $W$. Do health behaviors mediate the association between social capital and health? Prev Med 2006;43(6):488493.

5. Lindström M. Social capital, the miniaturisation of community and self-reported global and psychological health. Soc Sci Med 2004;59(3):595-607.

6. Bartkowski JP, Xu X. Religiosity and teen drug use reconsidered: a social capital perspective. Am J Prev Med 2007;32(6 Suppl): S182-S194.

7. Winstanley EL, Steinwachs DM, Ensminger ME, Latkin CA, Stitzer $\mathrm{ML}$, Olsen Y. The association of self-reported neighborhood disorganization and social capital with adolescent alcohol and drug use, dependence, and access to treatment. Drug Alcohol Depend 2008;92(1-3):173-182.

8. Takakura M. Does social trust at school affect students'smoking and drinking behavior in Japan?. Soc Sci Med 2011;72(2): 299306.

9. Wray-Lake L, Maggs JL, Johnston LD, Bachman JG, O'Malley PM, Schulenberg JE. Associations between community attachments and adolescent substance use in nationally representative samples. J Adolesc Health 2012;51(4):325-331.

10. Åslund C, Nilsson KW. Social capital in relation to alcohol consumption, smoking, and illicit drug use among adolescents: a cross-sectional study in Sweden. Int J Equity Health 2013;12:33.

11. Martins JG, de Paiva HN, Paiva PC, Ferreira RC, Pordeus IA, Zarzar PM, et al. New evidence about the "dark side" of social cohesion in promoting binge drinking among adolescents. PLoS One 2017;12(6):e0178652.

12. Seid AK, Hesse M, Bloomfield K. 'Make it another for me and my mates': does social capital encourage risky drinking among the Danish general population? Scand J Public Health 2016; 44(3):240-248.

13. Weitzman ER, Chen YY. Risk modifying effect of social capital on measures of heavy alcohol consumption, alcohol abuse, harms, and secondhand effects: national survey findings. J Epidemiol Community Health 2005;59(4):303-309.

14. Gao J, Weaver SR, Fua H, Pan Z. Does workplace social capital associate with hazardous drinking among Chinese rural-urban migrant workers? PLoS One 2014;9(12):e115286.

15. Loch MR, Souza RK, Mesas AE, Martinez-Gómez D, RodríguezArtalejo F. Relationship between social capital indicators and lifestyle in Brazilian adults. Cad Saude Publica 2015;31(8): 1636-1647.

16. Theall KP, DeJong W, Scribner R, Mason K, Schneider SK, Simonsen N. Social capital in the college setting: the impact of participation in campus activities on drinking and alcohol-related harms. J Am Coll Health 2009;58(1):15-23.

17. Greiner KA, Li C, Kawachi I, Hunt DC, Ahluwalia JS. The relationships of social participation and community ratings to health and health behaviors in areas with high and low population density. Soc Sci Med 2004;59(11):2303-2312.

18. Lindström M. Social capital, the miniaturization of community and high alcohol consumption: a population-based study. Alcohol Alcohol 2005;40(6):556-562.

19. Chuang YC, Chuang KY. Gender differences in relationships between social capital and individual smoking and drinking behavior in Taiwan. Soc Sci Med 2008;67(8):1321-1330.

20. Buonanno P, Vanin P. Bowling alone, drinking together. Empir Econ 2013;44(3):1635-1672.

21. Pavlova MK, Silbereisen RK, Sijko K. Social participation in Poland: links to emotional well-being and risky alcohol consumption. Soc Indic Res 2014;117:29-44.

22. Seid AK. Social interactions, trust and risky alcohol consumption. Health Econ Rev 2016;6(1):3.

23. Finlay AK, Ram N, Maggs JL, Caldwell LL. Leisure activities, the social weekend, and alcohol use: evidence from a daily study of first-year college students. J Stud Alcohol Drugs 2012;73(2): 250-259.

24. Ahnquist J, Lindström M, Wamala SP. Institutional trust and alcohol consumption in Sweden: the Swedish National Public Health Survey 2006. BMC Public Health 2008;8:283.

25. Lindström M. Social capital and health-related behaviors. In: Kawachi I, Subramanian SV, Kim D, editors. Social capital and health. New York: Springer; 2008, p. 221.

26. Reid MC, Fiellin DA, O'Connor PG. Hazardous and harmful alcohol consumption in primary care. Arch Intern Med 1999; 159(15):1681-1689.

27. Gmel G, Gutjahr E, Rehm J. How stable is the risk curve between alcohol and all-cause mortality and what factors influence the shape? A precision-weighted hierarchical meta-analysis. Eur J Epidemiol 2003;18(7):631-642.

28. Conigrave KM, Hall WD, Saunders JB. The AUDIT questionnaire: choosing a cut-off score. Addiction 1995;90(10):1349-1356. 
29. Babor TF, Robaina K. The Alcohol Use Disorders Identification Test (AUDIT): a review of graded severity algorithms and national adaptations. Int J Alcohol Drug Res 2016;5(2):17-24.

30. Jeong BG, Kim JR, Kang YS, Park KS, Lee JH, Jo SR, et al. < Field Action Report $>$ The strategies to address regional health inequalities in Gyeongsangnam-do: Health Plus Happiness Plus projects. J Agric Med Community Health 2012;37(1):36-51 (Korean).

31. Bajekal M, Purdon S. Social capital and social exclusion: development of a condensed module for the health survey for England. Social capital/social exclusion condensed module. London: National Center for Social Research; 2001, p. 32.

32. European Social Survey (ESS). ESS round 6 project instructions (PAPI); 2012 [cited 2019 Nov 26]. Available from: https://www. europeansocialsurvey.org/docs/round6/fieldwork/source/ ESS6_source_project_instructions.pdf.

33. World Health Organization. AUDIT: the Alcohol Use Disorders Identification Test: guidelines for use in primary health care; 2001 [cited 2019 Nov 21]. Available from: https://apps.who. int/iris/handle/10665/67205.

34. Office of Nutrition Policy and Promotion, Health Canada. Canadian Community Health Survey, cycle 2.2, nutrition (2004): income-related household food security in Canada; 2007 [cit- ed 2019 Nov 26]. Available from: http://www.hc-sc.gc.ca/fnan/surveill/nutrition/commun/income_food_sec-sec_alimeng.php\#metho25.

35. Lee BO, Lee CH, Lee PG, Choi MJ, Namkoong K. Development of Korean version of Alcohol Use Disorders Identification Test (AUDIT-K): its reliability and validity. J Korean Acad Addict Psychiatry 2000;4(2):83-92 (Korean).

36. Lundin A, Hallgren M, Balliu N, Forsell Y. The use of Alcohol Use Disorders Identification Test (AUDIT) in detecting alcohol use disorder and risk drinking in the general population: validation of AUDIT using schedules for clinical assessment in neuropsychiatry. Alcohol Clin Exp Res 2015;39(1):158-165.

37. Lundborg P. Social capital and substance use among Swedish adolescents--an explorative study. Soc Sci Med 2005;61(6): 1151-1158.

38. Lindström M. Social capital and the miniaturization of community among daily and intermittent smokers: a populationbased study. Prev Med 2003;36(2):177-184.

39. Rotenberg KJ. Loneliness and interpersonal trust. J Soc Clin Psychol 1994;13(2):152-173.

40. World Health Organization. Global Health Observatory indicator views; 2016 [cited 2020 Apr 23]. Available from: https:// apps.who.int/gho/data/node.imr. 